\title{
The quantitative genetics of wing dimorphism under laboratory and 'field' conditions in the cricket Gryllus pennsy/vanicus
}

\author{
DEREK A. ROFF* \& ANDREW M. SIMONS $\dagger$ \\ Department of Biology, McGill University, 1205 Dr Penfield Avenue, Montreal, Quebec, Canada, H3A $1 B 1$.
}

\begin{abstract}
Laboratory estimates of the heritability of threshold traits indicate a typically large additive genetic component. In natural populations, it has been suggested that the heritability might be considerably reduced owing to environmental variation. No test of this hypothesis for threshold traits has been undertaken. In this paper, such a test is reported using wing dimorphism in the cricket, Gryllus pennsylvanicus. A full-sib, split-family design was used, one half of each family being raised under constant conditions in the laboratory, and the second raised in cages outside at the site from which the parents were originally collected. Pitfall-trap data indicated that nymphs in the field cages grew similarly to individuals in the natural population. Heritability of wing dimorphism in the laboratory was larger than heritability in the 'field' $(0.70$ vs. 0.21 ). However, analysis of variation across environments suggested that the genetic correlation was close to or even 1.00: this is supported by the estimate of the genetic correlation of 0.94 . Thus selection in the laboratory environment will mirror the responses expected in the field. Laboratory estimates of heritability can therefore be useful indices of field values. These results do not support the hypothesis that heritabilities of threshold traits are reduced to insignificant values under natural conditions. More experiments are required to test the generality of this result and its consequences for the evolution of threshold traits in natural populations.
\end{abstract}

Keywords: evolution, genetic correlation, heritability, wing dimorphism.

\section{Introduction}

Threshold traits are traits that exhibit discrete phenotypic variation, but that are determined by a continuously distributed underlying trait; individuals above the threshold develop into one morph, whereas individuals below the threshold develop into the alternate morph (Falconer, 1989). Traits showing dimorphic variation that can be understood within this framework include paedomorphosis, wing dimorphism, weaponry in insects, trophic dimorphism in vertebrates, migratory behaviour, diapause, poecilogony, sex ratio and dimorphic mating behaviours (Roff, 1996). Heritability estimates of threshold traits of nondomestic animals reared under

\footnotetext{
${ }^{*}$ Correspondence. E-mail: droff@bio1.lan.mcgill.ca

†Present address: Department of Biology, Dalhousie University, Halifax, Nova Scotia, Canada B3H $4 \mathrm{~J} 1$.
}

laboratory conditions range from 0.12 to 0.98 , with a mean of 0.51 ( $\mathrm{SE}=0.064$; Table 1$)$. Thus, one-half of the phenotypic variation can typically be attributed to the action of additive genetic variation. Considering that many of these traits, such as dispersal behaviour, wing dimorphism and sex ratio, are probably under strong selection, it appears paradoxical that they should have such large heritabilities.

Bull et al. (1982) suggested that genetic variation for sex ratio in turtles may be maintained because variability in nest temperature, which determines sex, is very high. Assuming no covariance between temperature and genotype, Bull et al. (1982, p. 339) show that the effective heritability $\left(h_{\mathrm{e}}{ }^{2}\right)$ is $h^{2} V_{\mathrm{T}} /$ $\left(V_{\mathrm{P}}+V_{\mathrm{T}}\right)$, where $h^{2}$ is the heritability of sex ratio at a fixed temperature, $V_{\mathrm{P}}$ is the phenotypic variance and $V_{\mathrm{T}}$ is the variance in nest temperatures. For the map turtle, Graptemys ouchitensis, the phenotypic vari- 
Table 1 A review of experiments estimating heritability of threshold traits in nondomestic animals

\begin{tabular}{lllll}
\hline Character & Species & Organism & $h^{2}(\mathrm{SE})$ & Reference \\
\hline Feeding preference & Thamnophis elegans & Snake & $0.38(0.13) \dagger$ & Ayres \& Arnold (1983) \\
Wing morphology & Gryllus firmus & Cricket & $0.65(0.08)$ & Roff (1986) \\
& Allonemobius socius & Cricket & $0.62(0.15)$ & Mousseau \& Roff (1989a) \\
& Gryllus rubens & Cricket & $0.98(0.16)$ & Roff \& Fairbairn (1991) \\
& Dianemobius fascipes & Cricket & $0.30(0.04)$ & Masaki \& Seno (1990) \\
& Laodelphax striatellus & Planthopper & $0.32(\mathrm{n} . \mathrm{g})$. & Mori \& Nakasuji (1990) \\
Dispersal & Tetranychus urticae & Mite & $0.28(\mathrm{n} . \mathrm{g})$. & Li \& Margolies (1994) \\
Settling behaviour & Choristoneura rosaceanna & Caterpillar & $0.73(0.17)$ & Carrière \& Roitberg (1995) \\
& Spirorbis borealis & Polychaete & $0.27(0.10)$ & Mackay \& Doyle (1978) \\
Diapause & Allonemobius socius & Cricket & $0.74(0.16)$ & Mousseau \& Roff (1989b) \\
& Choristoneura rosaceanna & Caterpillar & $0.38(0.10)$ & Carrière (1994) \\
Sex ratio & Diaptomus sanguineus & Copepod & $0.60(0.35)$ & Hairston \& Dillon (1990) \\
& Nasonia vitripennis & Wasp & $0.12(0.02)$ & Parker \& Orzack (1985); \\
& & & & Orzack \& Gladstone (1994) \\
& Graptemys ouachitensis & Turtle & $0.82(0.25)$ & Bull et al. (1982) \\
Body size & Chelydra serpentina & Turtle & $0.56(0.15)$ & Janzen (1992) \\
& Oncorhynchus tshawytscha & Salmon & $0.32(0.14)$ & Heath et al. (1994) \\
\hline
\end{tabular}

$\uparrow$ Heritability estimated only on a $0-1$ scale, not underlying scale.

ance and nest variance were estimated as 0.09 and 1.00 , respectively, and $h^{2}$ as 0.82 (Bull et al., 1982). The effective heritability for the map turtle is thus 0.06 . Applying the same variance estimates to the heritability of sex ratio in the common snapping turtle, Chelydra serpentina, which is 0.56 (Janzen, 1992), gives an effective heritability of 0.04 . Both of these effective heritabilities are very low and, thus, much of the additive genetic variance exposed under constant conditions is effectively 'hidden' by the environmental variance in the natural world. This hypothesis has been advanced more generally for the maintenance of traits that phenotypically show continuous variation (Prout \& Barker, 1989; Riska et al., 1989). The argument rests on the assumption that the additive genetic variance, $V_{\mathrm{A}}$, is constant but that the environmental variance, $V_{E}$, is considerably larger in the field than the laboratory, thereby increasing $V_{\mathrm{P}}$ and decreasing $h^{2}$. Measurements of $V_{\mathrm{P}}$ in the laboratory and field do not bear this out, the increase being only about 20 per cent (Weigensberg \& Roff, 1997). Further, direct comparison of laboratory and field values of $h^{2}$ among a variety of species show no statistical difference (Weigensberg \& Roff, 1997).

Simons \& Roff (1995) examined the influence of natural variation on morphological variation in the cricket, Gryllus pennsylvanicus, by using a split-family design, rearing one half in a constant laboratory setting and the other half outside where the crickets were exposed to natural photoperiod and temperature (for simplicity referred to as the 'field'). Morphological traits (femur length, head width, thorax length and thorax width) had lower heritabilities in the 'field' (means of 0.30 and 0.33 for males and females, respectively) than in the lab. (0.51 and 0.59), but those of development time did not differ ('field' $h^{2}=0.45$ and 0.29 ; lab. $h^{2}=0.57$ and 0.43 , for males and females, respectively; Simons \& Roff, 1995). These data suggest that, although heritabilities may be somewhat reduced in the field, the reduction may not be as great as suggested by the analysis of Bull et al. (1982) for the heritability of sex ratio in turtles. The question of the effect of natural environmental variation on the heritabilities of threshold traits under natural conditions thus remains open and can only be answered by direct measurement.

Gryllus pennsylvanicus is wing dimorphic, some individuals possessing long wings (macropterous) and capable of flight, whereas others have only short wings (micropterous) and are flightless. Variation is strictly dichotomous (Harrison, 1979; Roff \& Simons, personal observations). In the northern part of its range very few of the adults are macropterous. However, because of the large number of individuals 
raised in the experiment reported above, sufficient numbers of macropterous females (no macropterous males) were obtained to estimate the heritability of wing dimorphism in both the laboratory and the 'field'. In this paper, we present the results of this analysis, estimating the heritabilities in the two environments and the genetic correlation between them.

\section{Materials and methods}

\section{Experimental design}

Full details of the experiment are reported in Simons \& Roff (1995); here we present only an overview. The field cricket, Gryllus pennsylvanicus, is a common North American cricket, univoltine throughout its range and overwintering as a diapausing egg. In Quebec (Canada) adults appear in late August and early September. During the autumn of 1990, 600 late instar nymphs were collected from a quarry on the McGill University field station at Mt. St. Hilaire, Quebec. These individuals completed development in the laboratory, and 200 male/female pairs were established in individual 4L buckets with food (rabbit chow and carrots) and a sandwich box filled with earth for oviposition of eggs. The eggs were kept at $4^{\circ} \mathrm{C}$ throughout the winter to satisfy diapause requirements and were incubated at $30^{\circ} \mathrm{C}$ in late May to initiate hatching. Hatchlings were collected during the 4-day period 13-16 days after removal from $4^{\circ} \mathrm{C}$. Offspring from 69 families were split into four equal groups, two reared under constant conditions in a growth chamber $\left(24^{\circ} \mathrm{C}, 17 \mathrm{~h}\right.$ light $/ 7 \mathrm{~h}$ dark photoperiod) emulating late summer conditions at the site of collection, and the second two were reared outside at Mt. St. Hilaire, where they received the same photoperiod/temperature regime as the natural population. The mean initial number per cage was $24.5(\mathrm{SD}=7.1)$, of which an average of 17.9 individuals per cage survived (Simons \& Roff, 1995). As a result of a failure of one cage, one family was dropped from the present analysis in order to preserve the balance. The mean number of females per family in the present analysis was 13.54 (lab.) and 18.21 (field). All crickets were fed an ad libitum diet of Purina rabbit chow and carrot.

Using previously collected data on hatching dates in the field, the initiation of the present experiment was timed to coincide as closely as possible with hatching in the field. This was checked using pitfall traps, which also provided data on the growth rate in the wild population. Temperatures in the field cages did not differ from the outside (Simons \& Roff, 1995). The spring of 1991 was unusually warm and egg hatch occurred earlier than expected. Although experiencing the same photoperiodic and temperature conditions as 'free-ranging' crickets, those grown in the field cages may have a more favourable diet and, hence, grow at a different rate from those in the natural population. Comparison of the growth rates of crickets from the field cages with those in the wild population showed that the growth curves were parallel, with the wild population being 14.6 days in advance of the field cage nymphs (Simons \& Roff, 1995). The nymphs in the field cages thus experienced similar conditions to the wild population.

\section{Statistical analysis}

The statistical analysis proceeded in three steps. First, we asked the question 'Is there significant variation attributable to family, site of rearing (lab. vs. field) and to an interaction between the two?'. Variation owing to family represents genetic variation, variation owing to site represents phenotypic plasticity, and the interaction indicates the strength of the genetic correlation between the environments. To address the above question, we computed the mean proportion macropterous per cage, giving two data points per family. The data were arcsine-square root transformed and then analysed using a two-way mixed model ANOVA (families taken as random and the environment as fixed effects).

In the next step, we estimated the genetic correlation between environments using the mixed model ANOva method described by Fry (1992). The data were not combined as above, but each individual was entered into the analysis separately, scored as 0 (micropterous) or 1 (macropterous). Although the use of such dichotomous data possibly violates the assumption of normality, Mercer \& Hill (1984) have shown that this approach gives an unbiased estimate of the genetic correlation. The covariance was estimated from the mixed model and the two variances from separate one-way anovas (Fry, 1992). A standard error cannot be determined directly from the analysis of variance results; to provide an approximate estimate we used a delete-one jackknife (Roff \& Preziosi, 1994).

Finally, heritabilities were estimated in each environment separately. As above, wing morph was scored as 0 and 1 and the heritability first estimated on this scale using a nested ANOVA to take into account possible cage effects (Elston, 1977). Full-sib estimates are potentially biased by dominance 
effects (Becker, 1985), but no such effects on the heritability of wing dimorphism have been observed in the sibling species, Gryllus firmus (Roff, 1986, 1990). To obtain the heritability on the underlying scale, the estimate was transformed according to the method of Robertson \& Lerner (1949; formulae given in Mousseau \& Roff, 1989a).

\section{Results}

There was a highly significant effect owing to site $\left(F_{1,67}=19.1, \quad P<0.0001\right)$ and family $\left(F_{67,136}=2.4\right.$, $P<0.0001)$, but no significant interaction $\left(F_{67,136}=\right.$ $0.6, P=0.98)$. Thus, there is both genetic variation for wing morphology and variation resulting from the rearing environment. The latter is evident from the difference in the proportion of macropterous females produced in the two environments [17.8 per cent in the lab. $(n=921)$, and 6.9 per cent in the field $(n=1238)]$.

A significant genetic correlation between laboratory and field is evident from the family mean correlation $(r=0.56, n=68, P<0.0001$, data arcsinesquare root transformed, Fig. 1). The correlation from family mean data underestimates the genetic correlation (Fry, 1992). The lack of an interaction found in the two-way ANOVA indicates that there is a constant difference between any two families in the proportion macropterous in the two environments. This suggests that the genetic correlation between the environments is close to unity. The genetic correlations estimated from the mixed model analy-

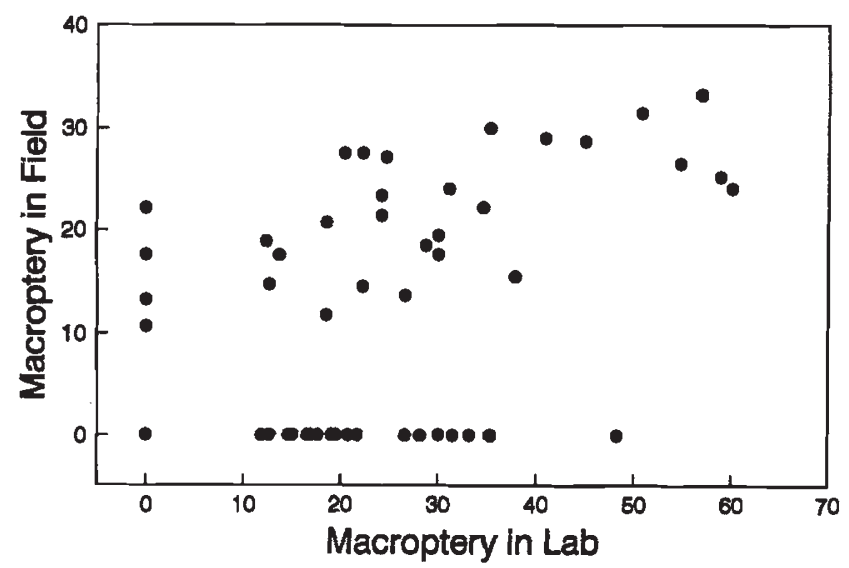

Fig. 1 Relationship between the proportion of macropterous females in the laboratory and field environments. Each point represents the data from a single family. Data transformed using the formula $Y=57.29 \times \operatorname{arcsine}(\sqrt{ } X)$, where $X$ is the proportion of macropterous females in a family within a particular environment. sis and jackknife method confirm this result; the analysis of variance estimate gave $r_{\mathrm{A}}=0.94$, and the jackknife estimate was $1.04(\mathrm{SE}=0.09)$.

Heritability of wing dimorphism estimated separately for the laboratory females was 0.70 $(\mathrm{SE}=0.19)$ and in the field it was $0.21(\mathrm{SE}=0.17)$. An approximate test of the difference between these two values can be obtained using the $t$-test (Sokal \& Rohlf, 1981, p. 228); because, as noted in the introduction, there is no a priori reason to expect heritability to be lower in the field (conventional wisdom notwithstanding), we used a two-tailed test but, for completeness, also report the results for a one-tailed test under the hypothesis that the field heritability will be lower than the laboratory estimate. The $t$-test shows no significant difference between laboratory and field for the two-tailed test $[t=(0.70-0.21)$ $/ \sqrt{ }\left(0.19^{2}+0.17^{2}\right)=1.92$, d.f. $\left.=134, P=0.06\right]$, but a significant difference for the one-tailed test $(P=0.03)$. The combined estimate is 0.46 $(\mathrm{SE}=0.18)$.

\section{Discussion}

The present results indicate that the heritability of wing dimorphism under laboratory conditions is approximately three times the value obtained under field conditions, although the difference is not statistically significant. This ratio is higher than the values obtained for other morphological traits in G. pennsylvanicus (1.6 for femur length, 2.1 for head width, 1.5 for thorax length, 1.8 for thorax width, 2.1 for ovipositor length; data from Simons \& Roff, 1995). Even if smaller than in the lab., the field heritability is certainly not negligible; thus, these data do not support the hypothesis advanced by Bull et al. (1982) that the effective heritability of a threshold trait is reduced under natural conditions to an insignificant value.

The analysis of the across-environment variation suggests that the genetic correlation between environments is close to 1.00 ; as a consequence, selection in one environment will be accompanied by a correlated response in the other environment. Using the individual estimates, the correlated response is $0.15 i \sqrt{ } V_{\mathrm{P}}$, where $i$ is the intensity of selection and $V_{\mathrm{P}}$ is the phenotypic variance in the 'unselected' environment. Assuming that the two heritabilities are the same $(0.46)$ gives a correlated response of $0.21 i \sqrt{ } V_{\mathrm{p}}$. In either case, there is potentially a significant correlated response. These results indicate that the genetic correlation between environments may be an important factor in the evolution of wing dimorphism, although more esti- 
mates across different types of environments are clearly needed. More importantly, a genetic correlation of 1.0 indicates that selection in the laboratory environment will mirror the results expected in the field and, hence, laboratory experiments have relevance to an understanding of evolution in the natural population.

Comparison of the growth in the field cages with the natural population indicates that nymphs in the field cages did experience conditions similar to those of the natural population. However, movement of the nymphs in the field cages was clearly restricted and it is still possible that the heritability might be lower in 'free-ranging' crickets. A second factor that might reduce the heritability in the natural population is the greater difference in hatching date between and within families. In the present experiment, a 4-day window was used, which encompasses 26 per cent of the numbers hatching (Simons \& Roff, 1995); nymphs hatching before or after this date would experience different photoperiod/ temperature regimes, which could further reduce heritability. Further experiments are required to examine these possibilities.

\section{Acknowledgements}

We are very grateful for the helpful comments of $Y$. Carrière and G. Stirling. This work was supported by an operating grant to D.A.R. from the Canadian Natural Sciences and Engineering Council.

\section{References}

AYRES, F. A. AND ARNOLD, S. J. 1983. Behavioural variations in natural populations. IV. Mendelian models and heritability of a feeding response in the garter snake, Thamnophis elegans. Heredity, 51, 405-413.

BECKER, w. A. 1985. Manual of Quantitative Genetics. McNaughton and Gunn Inc., Ann Arbor, MI.

BULL, J. J., VOGT, R. C. AND BULMER, M. G. 1982. Heritability of sex ratio in turtles with environmental determination. Evolution, 36, 333-341.

CARRIÈRE, Y. 1994. Evolution of phenotypic variance: non-Mendelian parental influences on phenotypic and genetic components of life-history traits in a generalist herbivore. Heredity, 72, 420-430.

CARRIÈRE, Y. AND ROITBERG, B. D. 1995. Evolution of hostselection behaviour in insect herbivores: genetic variation and covariation in host acceptance within and between populations of Choristoneura rosaceana (Family: Tortricidae), the obliquebanded leafroller. Heredity, 74, 357-368.

ELSTON, R. C. 1977. Estimating "heritability" of a dichotomous trait. Response. Biometrics, 33, 232-233.

FALCONER, D. S. 1989. Introduction to Quantitative Genet- ics, 3rd edn. Longman, New York.

FRY, J. D. 1992. The mixed-model analysis of variance applied to quantitative genetics: biological meaning of the parameters. Evolution, 46, 540-550.

HAIRSTON, N. G. J. AND DILLON, T. A. 1990. Fluctuating selection and response in a population of freshwater copepods. Evolution, 44, 1796-1805.

HARRISON, R. G. 1979. Flight polymorphism in the field cricket Gryllus pennsylvanicus. Oecologia, 40, 125-132.

HEATH, D. D., DEVLIN, R. H., HEATH, J. W. AND IWAMA, G. K. 1994. Genetic, environmental and interaction effects on the incidence of jacking in Oncorhynchus tshawytscha (chinook salmon). Heredity, 72, 146-154.

JANZEN F. J. 1992. Heritable variation for sex ratio under environmental sex determination in the common snapping turtle (Chelydra serpentina). Genetics, 131, $155-161$.

L1, J. AND MARGolies, D. C. 1994. Responses to direct and indirect selection on aerial dispersal behaviour in Tetranychus urticae. Heredity, 72, 10-22.

MACKAY, T. F. C. AND DOYLE, R. W. 1978. An ecological genetic analysis of the settling behaviour of a marine polychaete. I. Probability of settlement and gregarious behaviour. Heredity, 40, 1-12.

MASAKI, S. AND SENO, E. 1990. Effect of selection on wing dimorphism in the ground cricket Dianemobius fascipes (Walker). Bol. San. Veg. Plagas (Fuera de serie), 20, 381-393.

MERCER, J. T. AND HILL, W. G. 1984. Estimation of genetic parameters for skeletal defects in broiler chickens. Heredity, 53, 193-203.

MORı, K. AND NAKAsuJ1, F. 1990. Genetic analysis of the wing-form determination of the small brown planthopper, Laodelphax striatellus (Hemiptera: Delphacidae). Res. Popul. Ecol., 32, 279-287.

MousseaU, T. A. AND ROFF, D. A. 1989a. Geographical variability in the incidence and heritability of wing dimorphism in the striped ground cricket, Allonemobius fasciatus. Heredity, 62, 315-318.

MOUSSEAU, T. A. AND ROFF, D. A. 1989 b. Adaptation to seasonality in a cricket: patterns of phenotypic and genotypic variation in body size and diapause expression along a cline in season length. Evolution, 43, 1483-1496.

ORZACK, S. H. AND GLADSTONE, J. 1994. Quantitative genetics of sex ratio traits in the parasitic wasp Nasonia vitripennis. Genetics, 137, 211-20.

PARKER, E. D. AND ORZACK, S. H. 1985. Genetic variation for the sex ratio in Nasonia vitripennis. Genetics, 110, 93-105.

PROUT, T. AND BARKER, J. S. F. 1989. Ecological aspects of the heritability of body size in Drosophila buzzatii. Genetics, 123, 803-813.

RISKA, B., PROUT, T. AND TURELLI, M. 1989. Laboratory estimates of heritabilities and genetic correlations in nature. Genetics, 123, 865-871.

ROBERTSON, A. AND LERNER, 1. M. 1949. The heritability of all-or-none traits: viability of poultry. Genetics, 34, $395-411$. 
ROFF, D. A. 1986. The genetic basis of wing dimorphism in the sand cricket, Gryllus firmus, and its relevance to the evolution of wing dimorphisms in insects. Heredity, 57, 221-231.

ROFF, D. A. 1990. Selection for changes in the incidence of wing dimorphism in Gryllus firmus. Heredity, 65, 163-168.

ROFF, D. A. 1996. The evolution of threshold traits in animals. Q. Rev. Biol., 71, 3-35.

ROFF, D. A. AND FAIRBAIRN, D. J. 1991. Wing dimorphisms and the evolution of migratory polymorphisms among the insecta. Am. Zool., 31, 243-251.
ROFF, D. A. AND PREZIOSI, R. 1994. The estimation of the genetic correlation: the use of the jackknife. Heredity, 73, 544-548.

SIMONS, A. M. AND ROFF, D. A. 1995. The effect of environmental variability on the heritabilities of traits of a field cricket. Evolution, 48, 1637-1649.

SOKAL, R. R. AND ROHLF, F. J. 1981. Biometry, 2nd edn. W. H. Freeman \& Co., San Francisco.

WEIGENSBERG, I. AND ROFF, D. A. 1997. Natural heritabilities: can they be reliably estimated in the laboratory? Evolution (in press). 